\title{
Consequences of the Absence of Monotonicity of the NPV Function to the Assessment of the Effectiveness of Investment Projects
}

\section{Pawel Merlo}

\author{
University of Warmia and Mazury \\ R. Prawochenski 19, 10-719 Olsztyn, Poland \\ E-mail.merlo@uwm.edu.pl \\ cross $^{\text {ref }}$ http://dx.doi.org/10.5755/j01.ee.27.1.6334
}

\begin{abstract}
Discount methods do not pose difficulties in calculating and interpreting their outcome as long as the NPV function is monotonic. However, the loss of monotonicity can create obstacles to efficient applications of the mentioned methods. Thus, the thesis developed herein is that the major cause of problems encountered while calculating and interpreting profitability indices based on the discount technique is the course of the NPV function. The objective has been to identify and evaluate situations which may lead to the loss of monotonicity of the NPV, which in turn creates problems when making an assessment of the profitability of an investment and consequently can lead to an erroneous evaluation of the profitability of a planned investment project, whose assessment has been supported by discount methods. To this aim, the course of the function's variability has been scrutinized, and in particular zero points, the function's extreme values and intervals of monotonicity have been determined. The study has verified the research thesis and demonstrated that an assessment becomes more difficult when the NPV function's monotonicity is lost, which may lead to the appearance of more than one internal return rate. The current state of knowledge on this matter suggests that various modifications of such methods should be used in order to avoid any ambiguity of measures in case the NPV function is non-monotonic. However, it is not infrequent that instead of eliminating disadvantages of discount methods the said modifications lead to a mistaken interpretation of the achieved results. Then, a more radical solution is to use an NPV measure as one unburdened with errors originating from unconventional cash flows and to abandon measures like the IRR. However, this solution may also be incorrect because - despite obtaining a single NPV measure - its interpretation cannot be adequate due to the function's intervals in which the NPV increases together with an increasing discount rate, which can lead to an absurd conclusion that an investment project would become more profitable if the cost of capital was higher. Consequently, the methodology for evaluation of the profitability of investment projects employed until today cannot be considered as a correct approach as it may lead to making an unoptimal decision.
\end{abstract}

Keywords: Investments, Effectiveness of an Investment, Investment Effectiveness, Assessment Methods, NPV and IRR Criteria.

\section{Introduction}

Several methods applicable to an evaluation of the effectiveness of investment projects are most often categorized according to the time factor. This way we can distinguish static (simple) and dynamic (discount) methods. Static methods do not include the time factor. The biggest advantage of these methods lies in their simplicity, which makes them available to a broad circle of professionals. On the other hand, excluding time-related changes in the cash flow may lead to misinterpretation of a given investment. Thus, a decision to undertake an investment project by a company is best made relying on analyses which include the discount rate, i.e. discount methods. These methods take into account the time factor by analyzing cash outflows and inflows over a predetermined period of time, which enables a much more precise assessment of the project. These methods are applied to measure the effectiveness for particular investments.

Dynamic methods include:

- $\quad N P V-($ net present value);

- $\quad I R R-($ internal rate of return);

- $\quad M I R R-($ modified internal rate of return);
- $P I$ - (profitability index or B/C Ratio benefits/costs ratio);

- $\quad D P P$ - discounted payback period).

All these methods employ the discount rate method which reduces the cash surplus value in different years to the current value in the base year, thus facilitating comparability in time.

When attempting to find an answer to the question what cash surplus we are able to derive from a given investment, we should compare the investment inputs necessary to complete the project with the cash flows it will generate, which equates to calculating NPV. Other indices based on the discount rate technique can be perceived as mathematical transformations of NPV (IRR, $B / C$ Ratio, $D P P$ ) or possibly modifications of this index $(M I R R)$, thus in practice any analysis of currently existing indices can rely on an analysis of NPV. It can therefore be hypothesized that the correctness of NPV calculations implies the correctness of an investment assessment achieved with other discounted indices.

Including the residual value (RV), a formula for computing NPV may be written as below: 


$$
N P V=\sum_{t=1}^{n} \frac{C F_{t}}{(1+r)^{t}}-\sum_{t=1}^{m} \frac{I_{t}}{(1+r)^{t}}+\frac{R V}{(1+r)^{t}}
$$

In turn, the internal rate of return $(I R R)$ is defined as a discount rate at which the current value of investment cash inflows is level with the investment outlays. Thus, it is the discount rate at which NPV $=0$ (Russell \& Rickard, 1982; Marcinek, 1998; Osborne, 2010).

We can write down that:

$$
\sum_{t=1}^{n} \frac{C F_{t}}{(1+I R R)^{t}}-\sum_{t=1}^{m} \frac{I_{t}}{(1+I R R)^{t}}+\frac{R V}{(1+I R R)^{t}}=0
$$

With the IRR method, a project is approved for execution if the obtained value of IRR is higher than or equal to the discount rate, referred to as the threshold profit rate below which a given project is not worth investing in, in short MARR (minimum acceptable rate of return).

In practice, an application of the IRR method may either be difficult or impossible. Among the gravest problems while using this measure there are cases when the IRR assumes more than one value (Lorie \& Savage, 1955' Jean, 1968; Oehmke, 2000; Domingo, 2001; Joaquin, 2001). This will happen, for instance, when two IRR values appear. A situation like this can be encountered when large investment inputs occur in both the initial and final years (Torries, 1998; Yoon \& Choi, 2002). As a result, it is impossible to attain an unambiguous assessment of the effectiveness of a given investment project - a decision-maker is therefore confronted with a question which of the calculated IRRs is the actual internal rate of return for the analyzed project. If the rate adopted is too low, the project that would otherwise be profitable might be abandoned. Conversely, an excessively high IRR might lead to losses if the actual rate of return was lower. Importantly, a problem like this may have to be solved not only by a company which makes a decision whether or not to implement a given project but also by financial institutions involved in providing funds for the execution of the project. An erroneous assessment of the project's profitability may lead to a false assessment of the company's paying capacity and consequently to a loss of possibility to recover the funds lent to the investor.

A situation when a calculated value of an index (i.e. more than one value) does not allow an unequivocal interpretation of the effectiveness of a planned investment project leads to discarding the IRR measure as an assessment criterion. Consequently, the decision to implement (or abandon) a project is based on other discount measures, which yield only one value and therefore, theoretically, do not raise such problems in a project's assessment. The above solution seems reasonable, especially as it has been recommended in relevant literature for years, ever since the problem was first considered (Hirshleifer, 1958; Sugden \& Williams, 1978; Robison \& Barry, 1996; Jenkins \& Harberger, 1995; Belli, 1996; Tang \& Tang, 2003). Some economists have tried to solve the problem differently, for example Sulkowski (1999), who suggested some modification of existing cash flows (i.e. to modify 'non-standard' into 'standard' flows) so as to obtain a single IRR value.
Leaving aside serious doubts regarding the appropriateness of this type of modifications (for example, in the above approach, the value of IRR will change as the discount rate changes), more importantly the suggested approach does not solve the problem of an extremely specific nature of the distribution of such flows and issuing implications. Literature contains several other suggestions of how existing assessment methods and algorithms can be modified (e.g. Rocabert et al., 2005; Nwogugu, 2010; Altshuler \& Magni, 2012; Ben-Horin \& Kroll, 2012; Carey, 2012; Magni, 2013; Weber, 2014; Ng \& Beruvides, 2015). Colloquially speaking, it is wrong to 'treat symptoms of disease when in fact it is necessary to diagnose its causes'. Hence, it is essential to identify the reasons causing problems while using the IRR index and many others based on the discount technique. At the same time, it is worth recalling what has been already mentioned, namely that popular and widely used discount methods are no more than mathematical transformations of the NPV method, and difficulties using them must originate from the construction of the NPV function itself and its properties. Thus, there is no justification for modification of the NPV function derivaties (IRR, PI, DPP, etc.) without making changes to the construction of the NPV. In principle, any attempts at modifying the above derivative indices cannot be considered as a right one and sufficient for solving the discussed problem and cannot serve as the basis for an assessment of the profitability of investment projects in such cases. Regrettably, the problem is frequently neglected and unmentioned in numerous research papers or in publications offering guidelines and addressed to business entities involved in investment effectiveness evaluation. One possible reason is a small share of investment projects that lead to difficulties in the interpretation of the assessment results. However, a mere fact that difficult cases are sporadic does not justify their omission.

Thus, a starting point must consists in a modification of the algorithm applied to calculating the NPV, which will simultaneously force changes in constructions of other discount methods (or in general will be synonymous to those changes). Employing the existing methods and algorithms can lead to an erroneous assessment of the profitability of future investment enterprises and in consequence cause grave financial problems suffered by the entities directly and indirectly (e.g. credit providers) engaged in the investment process. It should be mentioned that despite numerous attempts at improving the existing discount methods, none has been convincing enough to bring about a revision and reduction of the use of classic discount methods, which is evidenced by the fact that in practice most companies and institutions use only unmodified methods, frequently being unaware of limitations to their applicability, as implicated by research conducted in many countries for years (Payne, Carrington Heath, Gale 1999; Kester et al., 1999; Graham \& Harvey, 2001; Ryan \& Ryan, 2002; Liljeblom \& Vaihekoski, 2004; Brounen et al., 2004; Merlo, 2008; Brealey et al., 2009; Kester \& Robbins, 2011; Correia, 2012; Mukherjee \& Rahahleh, 2013).

\footnotetext{
${ }^{1}$ The author intentionally cited also some older sources to rpesent an evolution of opinions (or their continuity) on the discussed subject.
} 
The most common reason is the inadequate knowledge of and attention given to the problem. Another reason is the fact that investors often use services of other companies for performing make such calculations. An investor may therefore remain completely unaware of the threat when an investment's effectiveness analysis will only comprise values of indices whose interpretation does not raise any doubts.

Thus, it is essential to identify causes and circumstances of the described phenomenon, which may provide grounds for the search for new solutions in calculating the profitability of investment projects. As mentioned earlier, discount methods used in practice are actually based on transformations of the NPV method. It is therefore necessary to analyze in detail courses of this function in various possible cases.

\section{Research Objective, Hypotheses and Methods}

Discount methods do not cause difficulties in calculating or interpreting their results as long as the NPV functions maintains monotonicity. However, a loss of the monotonicity of this function makes its application difficult, an example of which is the occurrence of more than one internal rate of return. The research objective was to analyze the course of the NPV function and to identify and evaluate situations possibly leading to the loss of the function's monotonicity, which would result in certain difficulties while making an assessment of the profitability of investment projects and consequently lead to erroneous interpretations of the said profitability.

The following hypotheses were adopted during the research:

H1: Correct results of calculations of the investment profitability indices based on the discount technique, as well as their correct interpretation are determined by the course of the NPV function;

H2: The loss of monotonicity of the NPV function makes useless all methods based on the discount technique in the profitability assessment of investment projects;

H3: The factor which determines the loss of monotonicity of the NPV function, and hence makes the discount methods useless is the appearance of negative cash flows subjected to discounting.

To achieve the above research objective and verify the hypotheses, our study focused on the course of variability of the function, and in particular on determination of the function's zero points, extreme values and intervals of its monotonicity. This approach enabled us to identify the cases when application of classical evaluation methods is not viable economically and therefore the usefulness of existing methods of investment profitability assessment based on discounted methods is undermined.

\section{Research Results}

When the simplest form of the NPV function is taken for analysis::

$$
\varphi=\sum_{t=1}^{n} \frac{c_{t}}{(1+r)^{t}}-I_{0}
$$

it is assumed the whole investment input is incurred in the zero time period, which means generating a cash flow $c_{t}$ in the subsequent years. Naturally, for an investment to make sense, the value of NPV must be positive, that is the generated sequence of payments $c_{t}$ must cover the initial investment inputs $I_{0}$.

The simplest, uncontroversial variant is a situation where the generated series of payments at any time points will be positive, i.e.

$$
\forall c \in R^{+}, \forall t \in T, \frac{d \varphi}{d r}=\sum_{t \in T}-c_{t} \cdot t(1+r)^{-t-1}<0
$$

Because $c_{t}>0$ is

$$
\sum_{t \in T}-t(1+r)^{-t-1}<0
$$

because $\mathrm{t}<-1$, which implies that:

$$
(1+r)^{-t-1}>0
$$

thus:

$$
\forall c \in R^{+}, \frac{d \varphi}{d r}<0
$$

meaning that $\forall c \in \mathbb{R}^{+}, \varphi(r)$ is decreasing within the interval $(-1, \infty)$. Obviously, in practice this means that because of a non-negative character of the interest rate (at least nominal one), the examined function is negative in the interval of $(0, \infty)$. This fact is very well understood from the point of economics, as a higher cost of capital determined by the level of a discount rate implies a lower level of generated cash inflows, thus causing a decrease in the value of NPV (figure 1).

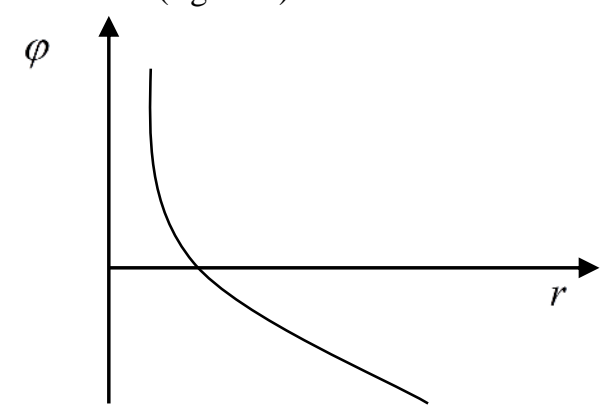

Figure 1. Monotonicity of $\varphi(r)$ at $c>0$

Certainly, the function will also be monotonic if:

$$
\begin{aligned}
& \forall c \in \mathbb{R}^{-}, \forall t \in T, \frac{d \varphi}{d r}=\sum_{t \in T}-c_{t} \cdot t(1+r)^{-t-1}>0 \\
& \forall c \in R^{-}, \forall t \in T, \frac{d \varphi}{d r}=\sum_{t=1}^{n}-t(1+r)^{-t-1}>0
\end{aligned}
$$

because $\mathrm{t}>-1$. However, this indicates the lack of coverage of the initial investment, which translates to the lack of profitability of a given investment, and this puts such a case beyond the scope of our interest.

The moment a negative cash flow appears in a series of payments, $c_{t} \varphi(r)$ may not continue to be monotonic:

$$
\begin{aligned}
& \exists p \exists C_{t}^{p} \in R^{n+1} \text { where } C_{t}^{p}=\left(C_{0}, C_{1}, C_{2} \ldots, C_{n}\right) \\
& \left\{C_{t}^{p}\right\}=\alpha\left(C_{t}^{p}\right) \cup \beta\left(C_{t}^{p}\right) \cup \gamma\left(C_{t}^{p}\right)
\end{aligned}
$$


for which $\varphi(r)$ is monotonic in intervals, which implies that it has at least one local extremum. The class of selected points $C_{t}^{p}$ can be considered in relation to the NPV function. Three separate subclasses are distinguishable:

$$
\begin{aligned}
& \alpha\left(C_{t}^{p}\right) \cap \gamma\left(C_{t}^{p}\right)=\phi \\
& \alpha\left(C_{t}^{p}\right) \cap \beta\left(C_{t}^{p}\right)=\phi \\
& \gamma\left(C_{t}^{p}\right) \cap \beta\left(C_{t}^{p}\right)=\phi
\end{aligned}
$$

Let :

$$
r \in[x, y] \text {, where } x, y \in R^{+} \cup\{0\} \text { and } x<y
$$

- subclass $\alpha\left(C_{t}^{p}\right)$ consists of the family of functions $\varphi(r)>0 \forall r$;

- subclass $\beta\left(C_{t}^{p}\right)$ consists of the family of functions for which $\varphi(r)$ assumes positive and negative values;

- subclass $\gamma\left(C_{t}^{p}\right)$ consists of the family of functions $\varphi(r)<0 \forall r$;

In subclass $\alpha\left(C_{t}^{p}\right)$ there are no zero points of functions, while subclass $\gamma\left(C_{t}^{p}\right)$ falls beyond our interest because of the negative values of the cash flow surplus, that is the unprofitability of the investment according to $N P V$ as a criterion. In subclass $\beta\left(C_{t}^{p}\right) N P V$ may assume both positive and negative values, which means that the function can have more than one zero point (figure 2).

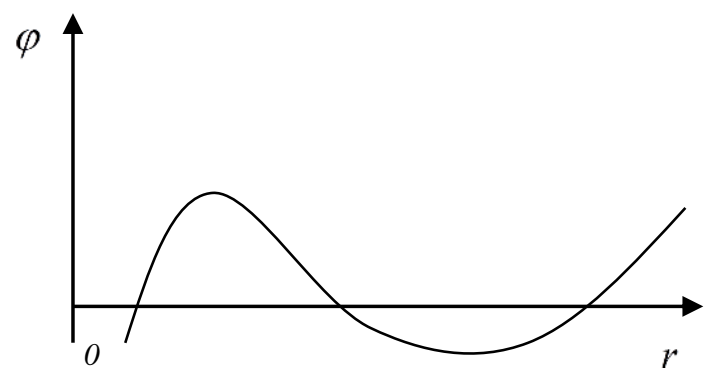

Figure 2. $\varphi(\mathrm{r})$ Monotonic in intervals in subclass $\beta\left(C_{t}^{p}\right)$

The number of roots of a function can be determined according to the Cartesian rule of signs, which means that the number of positive zeros of a polynomial is equal to the number of changes of the sign of coefficients or is less than that number by an even number. ${ }^{2}$

Let us take for our analysis one of the simplest variants from subclass $\beta\left(C_{t}^{p}\right)$ :

$$
\exists p \exists C_{t}^{p} \in \mathbb{R}^{n+1} \text { gdzie } C_{t}^{p}=\left(C_{0}, C_{1}, C_{2} \ldots, C_{n}\right) \text { and }
$$

$\exists\{x<y<z\} \in R^{+}: \forall k \leq n$ and if $\forall r \in[x, y]$,

where $\frac{d \varphi_{y}}{d r}=0, \quad \varphi_{k}(r) \geq \varphi(r): \frac{d \varphi}{d r}>0 \Rightarrow \varphi(r)$ is an increasing function in the interval $[x, y]$; if $\forall r \in[y, z]$ where $\frac{d \varphi_{y}}{d r}=0, \quad \varphi_{k}(r) \leq \varphi(r): \frac{d \varphi}{d r}<0 \Rightarrow \varphi(r) \quad$ is a decreasing function in the interval $[y, z]$, that is it is an NPV function growing initially but decreasing afterwards in the interval $[x, z]$. If this is the case, then there could be two zero points at the most of the function within the interval $[x, z]$, meaning no more than two IRR values. As mentioned before, in such cases the relevant references recommend to use the NPV method as the one which yields just one specific value. And in fact, when the NPV method is applied, there is an impossibility of obtaining several results, as may happen when the IRR method is used, but that does not mean that the occurrence of such a situation has no influence on the correctness of the obtained (just one) results of the discount net excess. If there is only one IRR value, the value of NPV decreases as the discount rate increases. This is quite understandable if we assume a higher, more demanding discount rate, we will obtain a lower NPV value. Thus, when accepting a higher MARR (i.e. minimum acceptable rate of return), we will obtain fewer investment projects which will satisfy the profitability condition. In turn, in this case the value of NPV increases with an increase of the rate of return to the $y$ value level. Having a set NPV value at discount rate $r_{0}$ in the range $(x, y)$ and wishing for example to adopt a more radical rate of return, that is from the range of $\left(r_{0}, y\right)$, we will obtain a higher NPV value, which means that although we have set more demanding conditions for the analyzed projects, we may find out that more of them will satisfy our conditions (figure 3, table 1).

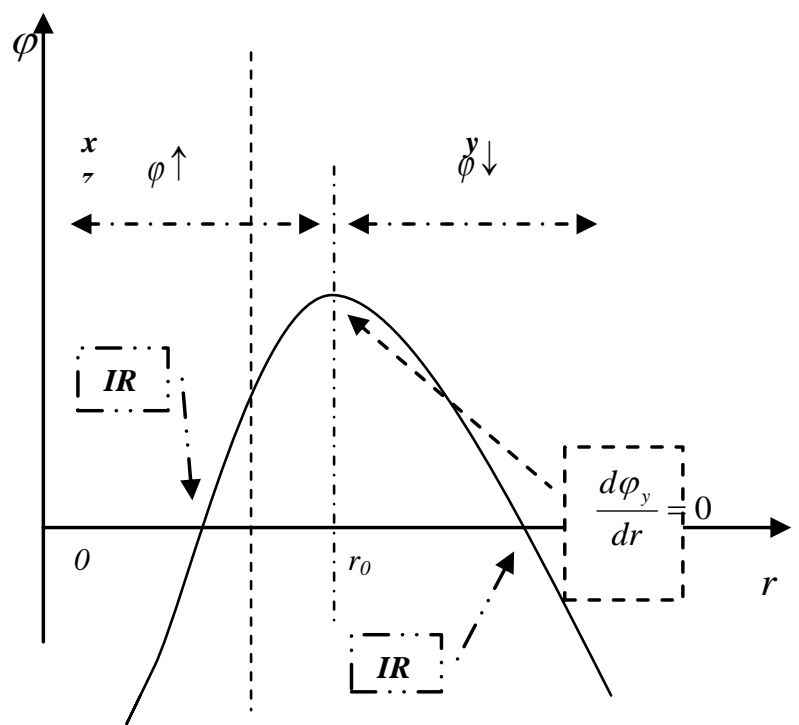

Figure 3. $\varphi(r)$ Monotonic in intervals in subclass $\beta\left(C_{t}^{p}\right)$ - two zero points

\footnotetext{
${ }^{2}$ the zero point of the NPV function in economics is referred to as the internal return rate - IRR
} 
$\varphi(r)$ Monotonic in intervals (interval $x, y)$ - the NPV value increases at the increasing discount rate value (an example)

\begin{tabular}{|c|c|c|c|c|c|c|c|}
\hline $\mathbf{t}$ & 0 & 1 & 2 & 3 & 4 & 5 & \\
\hline$c_{t}$ & -1500 & 1000 & 1000 & 1000 & 1000 & -2700 & \\
\hline $\mathbf{r}$ & $\mathrm{dc}_{0}$ & $\mathrm{dc}_{1}$ & $d c_{2}$ & $d c_{3}$ & $\mathrm{dc}_{4}$ & $\mathrm{dc}_{5}$ & $\varphi$ \\
\hline $1 \%$ & -1500 & 990.10 & 980.30 & 970.59 & 960.98 & -2568.96 & -166.99 \\
\hline $2 \%$ & -1500 & 980.39 & 961.17 & 942.32 & 923.85 & -2445.47 & -137.74 \\
\hline $3 \%$ & -1500 & 970.87 & 942.60 & 915.14 & 888.49 & -2329.04 & -111.95 \\
\hline $4 \%$ & -1500 & 961.54 & 924.56 & 889.00 & 854.80 & -2219.20 & -89.31 \\
\hline $5 \%$ & -1500 & 952.38 & 907.03 & 863.84 & 822.70 & -2115.52 & -69.57 \\
\hline $6 \%$ & -1500 & 943.40 & 890.00 & 839.62 & 792.09 & -2017.60 & -52.49 \\
\hline $7 \%$ & -1500 & 934.58 & 873.44 & 816.30 & 762.90 & -1925.06 & -37.85 \\
\hline $8 \%$ & -1500 & 925.93 & 857.34 & 793.83 & 735.03 & -1837.57 & -25.45 \\
\hline $9 \%$ & -1500 & 917.43 & 841.68 & 772.18 & 708.43 & -1754.81 & -15.09 \\
\hline $10 \%$ & -1500 & 909.09 & 826.45 & 751.31 & 683.01 & -1676.49 & -6.62 \\
\hline $11 \%$ & -1500 & 900.90 & 811.62 & 731.19 & 658.73 & -1602.32 & 0.13 \\
\hline $12 \%$ & -1500 & 892.86 & 797.19 & 711.78 & 635.52 & -1532.05 & 5.30 \\
\hline $13 \%$ & -1500 & 884.96 & 783.15 & 693.05 & 613.32 & -1465.45 & 9.02 \\
\hline $14 \%$ & -1500 & 877.19 & 769.47 & 674.97 & 592.08 & -1402.30 & 11.42 \\
\hline $15 \%$ & -1500 & 869.57 & 756.14 & 657.52 & 571.75 & -1342.38 & 12.60 \\
\hline
\end{tabular}

Thus, using the NPV measure in such an unconventional system of cash flows may lead to absurd results. This is why it is difficult to claim that the IRR method is worse than the NPV one because it generates two IRR values. The fact that more than one IRR value appears is synonymous to the fact that the NPV function is monotonic in intervals, which should alarm us about the unconventional and - in economic terms - absurd case, where using the IRR measure is just as doubtful as the application of NPV or any other value based on the discount technique. The presence of more than zero place is by no means an indication for discarding the IRR measure as a measure of the effectiveness of an investment project or for accepting the NPV value is an adequate one.

\section{Conclusions}

The performed analysis has shown that one of the key determinants of the practical usability of methods applied to the assessment of profitability of investments is the course of the NPV function, which is the consequence of cash flows generated by the investment project. A potential loss of monotonicity by the NPV function may cause difficulties in making an assessment of indices based on a discount technique. The most obvious albeit not an exclusive consequence of such a development is the occurrence of many zero points in the course of the NPV function, which is synonymous to the existence of multiple values of the IRR. This paper demonstrates that the currently available solutions to this problem are insufficient because they do not resolve the economic sense derived from the course of this function. When the discount net excess rises with a rising value of the discount rate, which occurs when the NPV function is rising in a certain interval, then it is difficult to give any economic interpretation of this phenomenon. This would imply that the investment's profitability might be enhanced by increasing the cost of capital, which obviously contradicts the principles of economics. It can thus be concluded that the proposed methods do not eliminate the core causes of the problem but merely focus on 'treating the symptoms' when they become notable. In addition, such modifications are frequently based on complicated algorithms, which remain incomprehensible to those working in the field, hence their actual use is extremely limited.

This paper has demonstrated that the factor directly responsible for the above situation is the occurrence of negative cash flows which are submitted to discounting, and this affects values of all indices based on the discount technique. Consequently, doubts are raised whether the available discount methods can be employed in practice not only when the NPV function loses monotonicity but also whenever negative cash flows, seen as a factor inducing 'the notable symptom' such as the aforementioned lost monotonicity, appear. Thus, the current methodology designed for assessment of profitability of investments cannot be considered as an adequate one, as it may lead, in some cases, to making unoptimal decisions. Application of the existing methods and algorithms can results in making erroneous assessments of the profitability of investment projects and lead to serious financial problems among business entities engaged in the investment process. However, this does not mean that using the currently available assessment methods based on the discount methods is not possible at all. Nevertheless, using them should be provided a firm basis of thorough knowledge about the limitations of these methods and situations when they are applicable. The loss of monotonicity by the NPV function completely excludes this option, as the current study demonstrates. Unfortunately, the knowledge possessed by individuals, enterprises and analysts using classical measures such as NPV, IRR and MIRR, etc. is very often insufficient, which may lead to formulating an inadequate assessment of the profitability of investment projects. 
Practical Implications and Recommendations to Users

Because profitability calculations for investment projects are currently most often performed with dedicated software packages, it is necessary to pre-select analyzed projects according to the criteria mentioned above, i.e. an overview of the monotonicity of functions and identification of the signs (+/-) of cash flows in individual years. In practice, depending on a case, the procedure can be represented by the algorithm ${ }^{3}$ (figure 4 ).

1) $\frac{d \varphi}{d r}>0$ - the project is discarded because it does not meet the profitability criterion and its further analysis is pointless;

2) $\frac{d \varphi}{d r}<0$ (monotonic function) and all CFs have positive values in individual years, therefore only positive

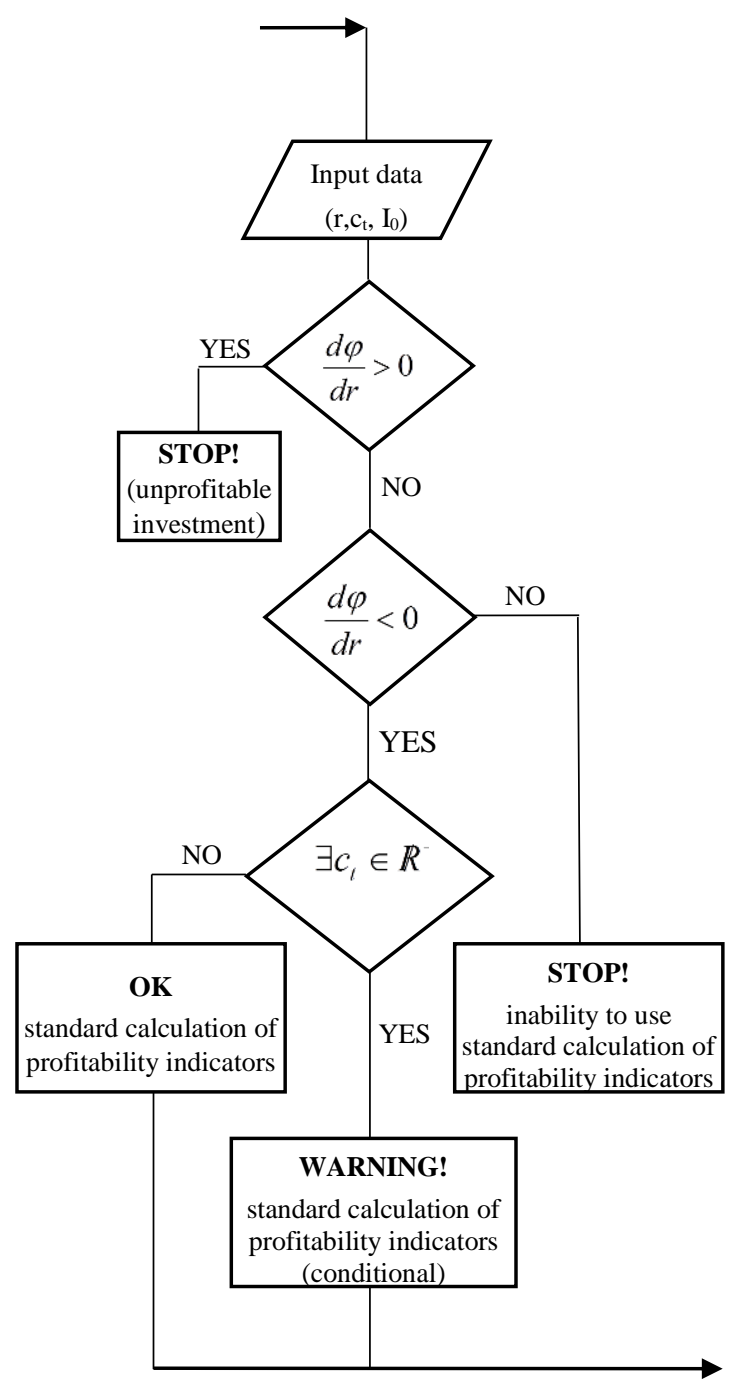

Figure 4. Algorithm of the pre-selection of investment projects, assuming that all of the inputs are made in the zero year.

values will be submitted to discounting - a standard financial analysis software package can be used to evaluate the profitability of the investment;

3) $\frac{d \varphi}{d r}<0$ (monotonic function) and at least one $\mathrm{CF}$ value outside the zero period (non-discounted value) assumes a negative sign - extreme caution is advised while calculating the effectiveness of the investment (i.e. conditional approval);

4) Non-monotonic function - profitability calculations should not be performed according to the standard discounting methods.

Noteworthy, the fourth case should exclude completely the use of existing discounting methods as credible ones when estimating the effectiveness of an investment project, while in the third case utmost care should be taken during their application - the function may still be monotonic but the appearance of negative $\mathrm{CF}$ values is a warning sign, as implicated earlier in this article. The above implications necessitate a new approach to the current state of knowledge on profitability assessment of investment projects and more effort should be taken to construct methods which will be free from the imperfections pointed to in the above paper.

\footnotetext{
3 the algorithm, same as the analysis accomplished before, applies to a case when the total inputs are expended in the zero year
} 


\section{References}

Altshuler, D., \& Magni, C. A. (2012). Why IRR is not the rate of return on your investment: Introducing the AIRR to the real estate community. Journal of Real Estate Portfolio Management, 18(2), http://dx.doi.org/10.2139/ssrn.1825544

Belli, P. (1996). Handbook on Economic Analysis of Investment Operations. Operations Policy Department, the World Bank, Washington, DC

Ben-Horin, M., Kroll, Y. (2012). The limited relevance of the multiple IRRs. The Engineering Economist 57(2), 101-118 http://dx.doi.org/10.1080/0013791X.2012.677113

Brealey, R., Myers, S., \& Allen, F. (2009). Principles of Corporate Finance (9th ed.). McGraw-Hill

Brounen, D., De Jong, A., \& Koedijk, K. (2004). Corporate finance in Europe: Confronting theory with practice. Financial Management, 33(4), 71-101 http://dx.doi.org/10.2139/ssrn.559415

Carey, S. (2012). Real estate JV promote calculations: Avoiding multiple IRRs, The Real Estate, Finance Journal, 27(4), 5-36

Correia, C. (2012). Capital budgeting practices in South Africa: A review. South African Journal Of Business Management, 43(2), 11-29.

Domingo, C. J. (2001). Anomalies in net present value calculations?, Economics Letters, 72(1), 127-129 http://dx.doi.org/10.1016/S0165-1765(01)00406-2

Graham, J., \& Harvey, C. (2001). The theory and practice of corporate finance: Evidence from the field. Journal of Financial Economics, 60, 187-243 http://dx.doi.org/10.1016/S0304-405X(01)00044-7

Hirshleifer, J. (1958). On the theory of optimal investment decisions. The Journal of Political Economy, 66(4), 329-352 http://dx.doi.org/10.1086/258057

Jean, W. H. (1968). On Multiple Rates of Return. Journal of Finance, 23(1), 187-191 http://dx.doi.org/10.1111/j.15406261.1968.tb03006.X

Jenkins, C., \& Harberger, A. (1995). Cost-Benefit Analysis of Investment Decisions. Harvard Institute for International Development, Cambridge, MA

Joaquin, D. C. (2001). Anomalies in net present value calculations? Economics Letters 72(1), 127-129 http://dx.doi.org/10.1016/S0165-1765(01)00406-2

Kester, G., Chang, R., Echanis, E., Haikal, S., Isa, M., \& Skully, M. (1999). Capital budgeting practices in the Asia-Pacific region: Australia, Hong Kong, Indonesia, Malaysia, Philippines and Singapore. Financial Practice and Education, 9(1), 25-33

Kester, G., \& Robbins, G. (2011). The capital budgeting practices of listed Irish companies: insights from CFOs on their investment appraisal techniques. Accountancy Ireland, 43(1), 28-30

Liljeblom, E., \& Vaihekoski, M. (2004). Investment evaluation methods and required rate of return in Finnish publicly listed companies. Finnish Journal of Business Economics, 53(1), 9-24

Lorie, J. H., \& Savage, L. J. (1955). Three Problems in Rationing Capital, The Journal of Business, 28, 229-239 http://dx.doi.org/10.1086/294081

Magni C.A. (2013). The Internal-Rate-of-Return approach and the AIRR paradigm: A refutation and a corroboration, The Engineering Economist, 58(2), 73-111 http://dx.doi.org/10.1080/0013791X.2012.745916

Marcinek, K. (1998). Finansowa ocena przedsięwzięć inwestycyjnych przedsiębiorstw. Wydawnictwo Uczelniane Akademii Ekonomicznej im. Karola Adamieckiego w Katowicach. Katowice

Merlo, P. (2008). Использование предприятиями методов оценки эффективности инвестиций для принятия будущих решений. Новые технологии в машиностроении - специиальный выпуск - Вопросы проектирования и производства конструкиий летательных аппаратов, 3 (54), 118-123

Mukherjee, T. K., \& Al Rahahleh, N. M. (2013). Capital Budgeting Techniques in Practice: U.S. Survey Evidence. Capital Budgeting Valuation: Financial Analysis for Today's Investment Projects, 151-171

Nwogugu, Michael, C. I. (2010), On Regret Theory, and Anomalies in Polynomials and Net-Present-Value Decisions, SSRN. September 10, http://dx.doi.org/10.2139/ssrn.1925458 http://dx.doi.org/10.2139/ssrn.1925458

Oehmke, J. F. (2000). Anomalies in net present value calculations. Economics Letters 67, 349-351 http://dx.doi.org/10.1016/S0165-1765(99)00271-2

Osborne, M. J. (2010). A resolution to the NPV-IRR debate? The Quarterly Review of Economics and Finance 50(2), 234-239 http://dx.doi.org/10.1016/j.qref.2010.01.002

Payne, J., Carrington Heath, W., \& Gale, L. (1999). Comparative financial practice in the US and Canada: Capital budgeting and risk assessment techniques. Financial Practice and Education, 9(1), 16-24

Robison, L. J., \& Barry, P. J., (1996). Present Value Models and Investment Analysis. The Academic Page, Northport, AL 
Pawel Merlo. Consequences of the Absence of Monotonicity of the NPV Function to the Assessment of the...

Rocabert, J. P., Tarrio, J. A., \& Perez, M. J. (2005). Anomalies in net present value calculations. A solution. Hacienda Pública Española/Revista de Economía Pública, 173(2), 47-60

Russell, A. M., \& Rickard, J. A. (1982). Uniqueness of Non-Negative Internal Rate of Return. Journal of the Institute of Actuaries, 109(3), 417-433 http://dx.doi.org/10.1017/S0020268100036325

Ryan, P., \& Ryan, G. (2002). Capital budgeting practices of the Fortune 1000: How have things changed? Journal of Business and Management, 8(4), 355-364

Sugden, R., \& Williams, A. (1978). The Principles of Practical Cost-Benefit Analysis. Oxford University Press, Oxford

Sulkowski C. (1999). O możliwości ujednolicenia wyboru inwestycji wedlug kryteriow NPV i IRR. Przegląd Organizacji, $5,29-32$

Tang, S. L., \& Tang, H. J. (2003). Technical note - the variable financial indicator IRR and the constant economic indicator NPV. The Engineering Economist, 48 (1), 69-78 http://dx.doi.org/10.1080/00137910308965052

Torries, T. F. (1998). NPV or IRR? Why not both? Mining Engineering, 50(10), 69-73

Weber, T. A. (2014). On the (non-)equivalence of IRR and NPV. Journal of Mathematical Economics 52, 25-39 http://dx.doi.org/10.1016/j.jmateco.2014.03.006

Yoon, Y., \& Choi, Y. (2002). Net Present Value And Modified Internal Rate: The Relationship. International Journal of Finance, 14(3), 2374-2379.

The article has been reviewed.

Received in January 2014; accepted in February, 2016. 